\title{
Reviews
}

\section{Marketing to the ageing consumer: The secrets to building an age-friendly business}

\author{
Dick Stroud and Kim Walker
}

Palgrave Macmillan; 2013; £19.99; 264pp;

ISBN: 9780230378193

Journal of Direct, Data and Digital Marketing Practice (2013) 14, 276-278. doi:10.1057/dddmp.2013.1

Fifteen years ago, the notion that life on our planet would be unsustainable in the absence of a wholesale review of the processes of production was propounded by a small minority, easily dismissable as cranks. Today, every Chief Executive trumpets the commitment of his or her company to saving the planet through its policy regarding the use of sustainable resources.

Equally urgent, according to Stroud and Walker's book 'Marketing to

Consumers are ageing

\section{Ageing affects many more consumers than businesses realise} the Ageing Consumer', are the actions that businesses will need to take to adapt to a world in which 'older' people form the disproportionate majority of the consuming public. Even by 2020, 40 per cent of Japanese adults will have reached their 60th birthday. How alert is business to the impact this is bound to have on the design of products and services, on the way benefits are communicated and the manner in which suppliers and consumers engage with each other in retail, call centre and web environments? The answer is hardly at all.

According to the authors, the businesses that have started on this journey - and Apple is cited as an example - are the exception rather than the rule. Their intention is for this book to act as a wake up call to Chief Executives and Corporate Strategists both by documenting the nature of the problem, which it does in impressive statistical detail, and through the practical framework which it provides to help them address the issue.

Their argument can be summarized as follows. The transformation of the age distribution of the consuming public is reflected neither in the design of marketing communications, nor in product design nor in the environments in which consumers interact with suppliers. By contrast, business persists in misinterpreting the grey market as one for which separate products are appropriate, whether stair lifts, hearing aids or incontinence pads, by virtue of the needs of a very small very elderly population who suffer quite serious impairments to their mobility or physical capabilities.

Evidence from the study of the ageing process suggests that this group forms a very small and extreme tip of a very much larger penumbra of people in whom the ageing process is already having a material but less significant impact in terms of their capabilities. Graying and loss of hair are examples of ageing processes that are 


\section{It is not the case that older people don't buy new products or switch brands}

\section{Consulting format supported by a website}

\section{Instructions, packaging, serious problems}

highly visible. Though presenting various product opportunities, the extent to which they impair the capabilities of those who experience them is relatively immaterial. There are many other aspects of the ageing process which are much less visible than baldness and grey hair, but which nonetheless have a significant effect on the ease with which people aged 50 and over can engage as consumers.

At the most basic level the ageing process affects the ability to cope with ambience noise, to comply accurately with complex instructions, to manage mechanical tasks such as opening packaging, to respond in adequate time to moving images on a website and to interpret information displayed using unfamiliar formats.

The disregard of the effects of these impediments by people involved in product design and service delivery result largely from their lack of awareness of these less visible forms of ageing. However, their neglect is compounded by an institutional deafness to evidence and too easily justified by the argument that people affected by the ageing process are among the least likely to switch to new brands or to experiment with new product categories. The Ipad and the luxury car market are cited as evidence to the contrary.

It is argued that this presumption persists as a result of the inexperience of product designers, web developers and communications professionals and the preoccupation of senior managers with short term financial and market share targets.

These arguments are presented in a simple and very easy to follow format structured in four sections. These cover the evolution of the practice of marketing to older people; detailed information on the process whereby ageing affects various capabilities and how these processes need to be accounted for in touch point design; the development of metrics for assessing the age friendliness of the brand and service; and the best way to implement a corporate strategy for improving the age friendliness of services.

The book conforms to good consulting practice by telling readers at the start of each section what it is that they are going to learn and reminding them at the end of each section the key points that they have been told. A number of business opportunities are highlighted relevant to the particular ageing processes covered in each section.

This format forms a natural introduction to a website containing more detailed information and tools for measuring the age friendliness of existing touch points.

Although the title implies that the book is relevant to marketing, which it undoubtedly is, its relevance is probably even greater for those responsible for managing retail operations and call centres. Within marketing communications, it should be a particularly valuable source of information for web developers.

Many of the problems illustrated in the book originate from poor practice among manufacturers, particularly in relation to instructions, packing and signage and greater emphasis might have been given to the role retailers might play in imposing age friendliness standards on their suppliers much as they now do in regards to sustainability. 
凉 Reviews

\section{Are businesses as customer-centric as they claim to be?}

\section{Making data accessible to a wider audience}

\section{Marketing beyond Dunbar's Number}

\section{CRM projects forgot to get the data right}

Organizationally, one cannot underestimate the challenge to organizations of re-engineering their systems to recognize the impact of the ageing process. However, it reflects poorly on many organizations' claim to customer-centricity that these requirements of their customers have not already been identified. It is equally disturbing to realize how ineffectual feedback from older people has been in making suppliers aware of so many improvements to their service that could be implemented often at virtually no additional cost. Were there a corporate will to do so thankfully this would be a much less costly challenge to address than climate change.

Richard Webber Hon F IDM

\section{In data we trust: How customer data is revolutionizing our economy}

Björn Bloching, Lars Luck and Thomas Range

Bloomsbury: London; 2012; £20.00; 213pp;

ISBN: 978-1408179512

Journal of Direct, Data and Digital Marketing Practice (2013) 14, 278-280. doi:10.1057/dddmp.2013.11

Books about data are few and far between. One of the challenges I faced when putting together the IDM Award in Data Management during 2010 was coming up with a satisfactory reading list. What is available divides between the very technical — 'Handbook of Statistical Analysis and Data Mining Applications' by Robert Nisbet, John Elder and Gary Miner (Academic Press, US, 2009 £56.99, ISBN: 978-0123747655), for example — and a handful of broader business titles such as 'The Data Asset' by Tony Fisher (John Wiley \& Sons, US, 2009, £30.99, ISBN: 978-0470462263).

Hence, the arrival of 'In Data We Trust', first published in German in 2011 as 'Data Unser', is to be welcomed. It sits comfortably into that category of books which take a technical subject and make them accessible to a wider audience, as was the case when Don Peppers and Martha Rogers published 'The One-to-One Future' in 1998.

This is an apt reference point as the heart of the first chapter goes over much of the same territory - the need to return to the same level of understanding of the customer which small shopkeepers used to have. As they note, modern businesses have too many customers to handle this way, even if social media appears to offer a new way to do it. (There is a pointed reference here to 'Dunbar's Number', which posits that a person can only maintain relationships with up to 150 friends.)

Although much of this territory is familiar, the book provides some useful German examples, which will be unfamiliar to English-speaking readers, such as Groupe Casino and Dodenhof. They are a refreshing change from the overexposed touch points of Tesco and Wal-Mart (although both get a name check here). 